\title{
A IMIGRAÇÃO ITALIANA NO ESPÍRITO SANTO: ANÁLISE DAS ABORDAGENS DO JORNAL O CACHOEIRANO E A OBRA DO CÔNSUL CARLOS NAGAR
}

\author{
Amanda Caetano ${ }^{1}$ \\ Helen Gomes do Nascimento ${ }^{2}$ \\ Maria Eduarda Soares Ferreira ${ }^{3}$ \\ Prisciliana Costa Ventura ${ }^{4}$ \\ Mateus Augusto Almeida Martins ${ }^{5}$ \\ Victor Silva Salaroli do Nascimento ${ }^{6}$ \\ Mellina de Fátima Neres de Sousa Curty ${ }^{7}$
}

Resumo: Para a elaboração deste trabalho, utilizamos as informações de documentos do século XIX e XX sobre a imigração italiana no Espírito Santo, nas visitas feitas ao IHGA (Instituto Histórico e Geográfico de Alegre), e nos embasamos no livro do Cônsul Carlo Nagar, que explica detalhadamente a chegada dos imigrantes italianos ao Espírito Santo, caracterizando suas dificuldades. Conjuntamente, analisamos o jornal O Cachoeirano que relata como foi a chegada dos primeiros imigrantes no Espírito Santo, bem como se deu o processo de incentivo à imigração na Província do Espírito Santo.

Palavras-chave: Imigração; Província do Espírito Santo; Jornal O Cachoeirano.

\footnotetext{
${ }^{1}$ Ensino Fundamental, Brasil. E-mail: amandacaetano89@gmail.com.

2 Ensino Fundamental, Brasil. E-mail: hgomesnascimento@hotmail.com.

${ }^{3}$ Ensino Fundamental, Brasil. E-mail: mariaeduardasf@gmail.com.

${ }^{4}$ Especialista em Filosofia Moderna e Contemporânea, Brasil. E-mail: lilaventura@hotmail.com.

${ }^{5}$ Graduado em História, Brasil. E-mail: m_ateusaugusto@hotmail.com.

${ }^{6}$ Graduando em História, Brasil. E-mail: victorsalaroli26@hotmail.com.

${ }^{7}$ Mestre em História, Brasil. E-mail: mell.curty@gmail.com.
} 